\title{
The Firing Temperature of Romanesque Brick from Pác
}

\author{
Rudolf Podoba $^{1,2}$, Igor Štubňa ${ }^{2}$, Jozefa Lukovičová ${ }^{1}$, Peter Bačík ${ }^{3}$ \\ ${ }^{1}$ Slovak University of Technology \\ Faculty of Civil Engineering, Department of Physic \\ e-mail: rudolf.podoba@stuba.sk, jozefa.lukovicova@stuba.sk \\ ${ }^{2}$ Constantine The Philosopher University in Nitra \\ Faculty of Natural Sciences, Department of Physic \\ e-mail: rudolf.podoba@ukf.sk, istubna@ukf.sk \\ ${ }^{3}$ Comenius University \\ Faculty of Natural Sciences, Department of Mineralogy and Petrology \\ e-mail: bacik@fns.uniba.sk
}

\begin{abstract}
A pavement brick taken from a Romanesque part of the church in Pác, in the Trnava County, Slovakia, was investigated by x-ray diffraction analysis (XRD) and thermal analyses as differential thermal analysis (DTA), thermogravimetry (TG) and thermodilatometry (TD). It was found that the brick contained dehydroxylated illitic clay, calcite and quartz. As revealed, dehydroxylation was completely finished and no redehydroxylation was observed. Partial decomposition of calcite was also found. The estimated firing temperature is between $600{ }^{\circ} \mathrm{C}$ and $700{ }^{\circ} \mathrm{C}$.
\end{abstract}

Key words: building ceramics, ancient ceramics, firing

\section{Introduction}

Sun-dried mud bricks are one of the oldest known building materials, dating back to $7000 \mathrm{BC}$. Fired bricks, which were probably discovered by the Romans, were more resistant to harsher weather conditions and much more reliable for use in permanent buildings. During the 12th century, bricks were reintroduced to Germany from Italy, and, later, brickmaking spread to Central Europe. To learn about our history is not just to analyze and preserve building ceramic objects but also to investigate and understand the knowledge and skills used to produce them [1]. This is important in the renovation of historic buildings where damaged material has to be replaced with new material, the properties of which should be close to the properties of the historic material. To reveal the basic physical properties of historic building ceramics is beyond the capacity of standard archaeological techniques. Therefore, one has been able to observe the exploitation of thermal analyses for better definiteness of results 
obtained from analysis of archaeological excavations in the past 40 years. X-ray diffraction analysis (XRD) and thermal analyses, especially differential thermal analysis (DTA), thermogravimetry (TG) and thermodilatometry (TD) are successfully applied to the study of historic building ceramics, such as bricks and tiles.

The most frequent object of the thermoanalytical study of historic ceramics is the estimation of the firing temperature [2]. The estimation is based on comparison of the TG, DTA and TD curves received from the historic ceramic sample with the curves received from laboratory prepared samples [2]. The last are known for the most probable constituents of ceramic clay such as kaolinite, illite, montmorillonite, muscovite, calcite, quartz and feldspar. These minerals change their structure as well as their composition (except quartz and feldspar) if subjected to heating up to $950{ }^{\circ} \mathrm{C}$, which is the maximum temperature used for the firing of ancient ceramics.

Every method used for the investigation of ancient ceramics, that exploits some kind of thermal analysis, is based on evaluation of the degree of conversion. It is known that phyllosilicates (kaolinite, illite, montmorillonite, muscovite) and calcite change irreversibly if heated at a temperature that is within the interval of dehydroxylation of relevant phyllosilicate and within the interval of calcite decomposition.

Degree of conversion, which characterizes phase transformation of phyllosilicate or calcite during firing, depends on the temperature and time, $\alpha=f(T, t)$, if measured on small powder sample. A different situation exists in a large ceramic body such as a brick. Layers which are on the surface are transformed sooner than the layers inside the brick. Experiments on large cylindrical samples $(\varnothing 80 \mathrm{~mm})$ showed clear dependence of the degree of kaolinite $\rightarrow$ metakaolinite conversion on the location of the small sample taken for TG. Consequently, $\alpha=f(T, t, r)$, where $r$ is the distance of the sample from the axis of rotation. It was also found that after heating at $650{ }^{\circ} \mathrm{C}$ for $10 \mathrm{~h}$ degree of conversion reached $\sim 0.95$ and practically did not depend on $r[3,4]$.

In simple field kilns, which were used locally in Slovakia for firing the bricks up to the first half of the $20^{\text {th }}$ century, the fuel was beech wood [5]. Green bricks were prepared by moulding the plastic mass made from local clay, silica sand and water. Then the bricks were dried in the place protected against rain for several weeks and finally inserted into the kiln and fired. The firing process consisted from three steps. The first step was run at a low temperature to finish the remove of the physically bound water from pores. The second step was increasing the temperature up to maximum determined by the technical capability of the kiln [6]. As reported in [7], the upper temperature limit in such simple kiln is $700{ }^{\circ} \mathrm{C}$. And the third step was slow cooling. The whole firing cycle took $\sim 7$ days in the small simple field kiln. The temperature was not measured. We can assume that a similar method and equipment were used for firing the bricks for the Romanesque church in Pác sometime in $13^{\text {th }}$ century.

In this paper, the study is focused on the analysis of the bricks from the church in Pác. Our goal was to estimate the firing temperature. 


\section{Experimental}

The samples were pavement bricks from a church located in Pác, Trnava County, Slovakia. The church was originally built in the Romanesque style, later was rebuilt in the Gothic style and enlarged in the Baroque style. The pavement bricks, which are the object of this study, become from the oldest part of the church. The bricks were located under a newer Gothic pavement.

DTA and TG were performed on the modernized analyzer Derivatograph $1000^{\circ}$ (Hungary) using compact sample of $10 \times 10 \times 20 \mathrm{~mm}$ cut from the surface layer of the brick and heating rate of $5^{\circ} \mathrm{C} / \mathrm{min}$ [8]. A reference compact sample of the same size was made from a pressed powder $\mathrm{Al}_{2} \mathrm{O}_{3}$. TD was done on the dilatometer described in [9] with the sample $10 \times 10 \times 40$ $\mathrm{mm}$ at the heating rate $5{ }^{\circ} \mathrm{C} / \mathrm{min}$.

The XRD analysis was performed by the diffractometer Bruker D8 Advance with $\mathrm{Cu}$ anticathode $(\lambda \alpha 1=1.54060 \AA)$, accelerating voltage $40 \mathrm{kV}$ and beam current $40 \mathrm{~mA}$. Data were obtained by the Bruker LynxEye detector.

\section{Results and discussion}

The results of XRD analysis of the Romanesque brick are illustrated in Fig. 1. Here, reflections of the four minerals are seen. Quartz and feldspar do not change their structure at firing temperatures lower than $1100{ }^{\circ} \mathrm{C}$. Calcite is also present in the brick, which shows that the firing conditions were not sufficient for its full decomposition. A remnant of illite was also found.

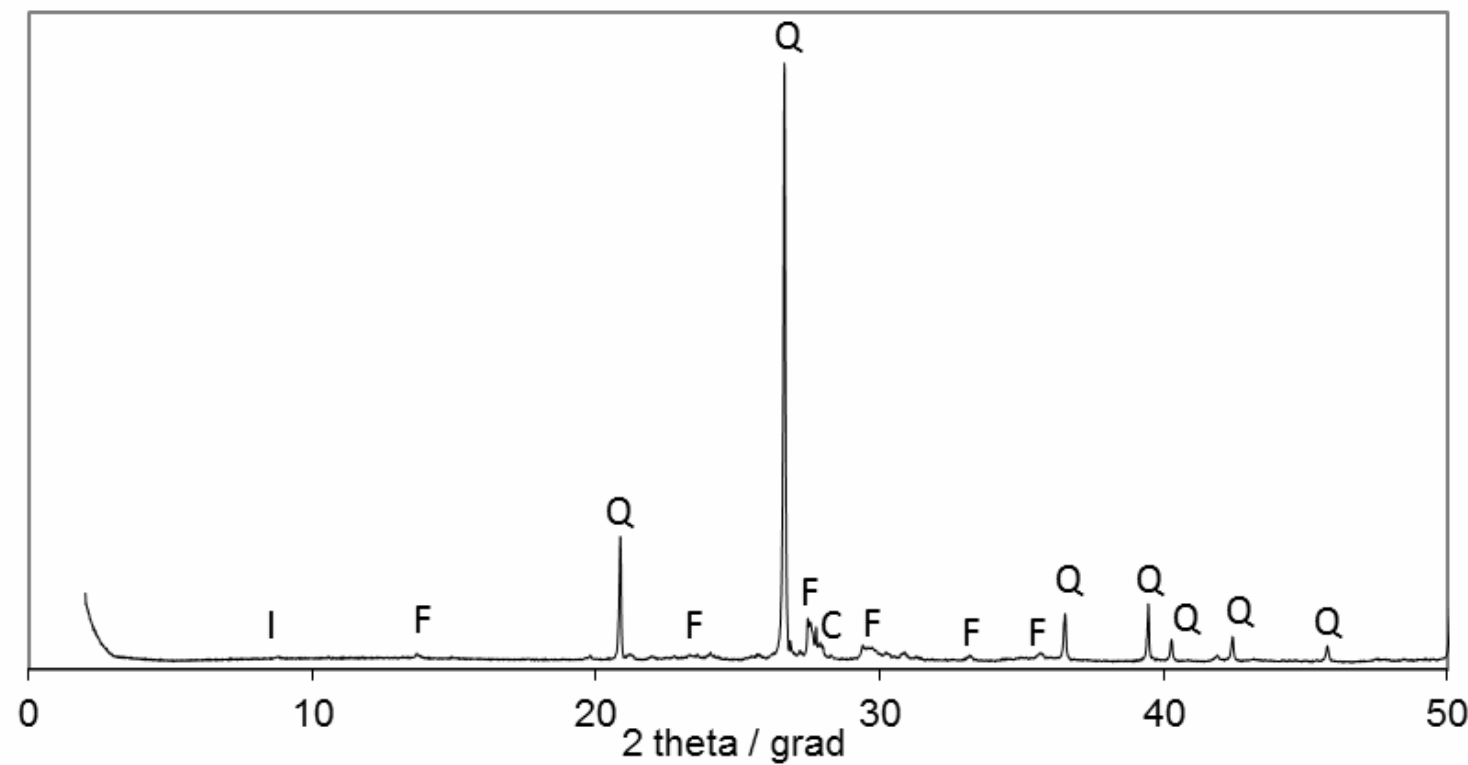

Figure 1: XRD pattern of the Romanesque brick. Q - quartz, F - feldspar, C - calcite. I - illite 
The results of thermal analyses DTA and TG are illustrated in Fig. 2. The first endothermic minimum on the DTA curve, which belongs to the interval of $20-300{ }^{\circ} \mathrm{C}$, is typical for porous building clay ceramics, which do not contain glassy phase, i.e. fired at a relatively low temperature. The minimum is related to liberation of the physically bound water absorbed on the faces of the crystals of minerals. It is known that porosity of the green porcelain body increases $4-5 \%$ during dehydroxylation [10] and the specific surface of kaolin body increases from 11 to $15 \mathrm{~m}^{2} / \mathrm{g}$ during this reaction [11]. In spite of the higher porosity after dehydroxylation, dehydroxylated ceramic body can absorb fewer water molecules than a green body. This can be explained by improved mechanical strength of the samples after dehydroxylation and less capability of the dehydroxylated samples to expand [12]. This fact was also observed in ancient ceramics investigated in $[2,13,14]$.

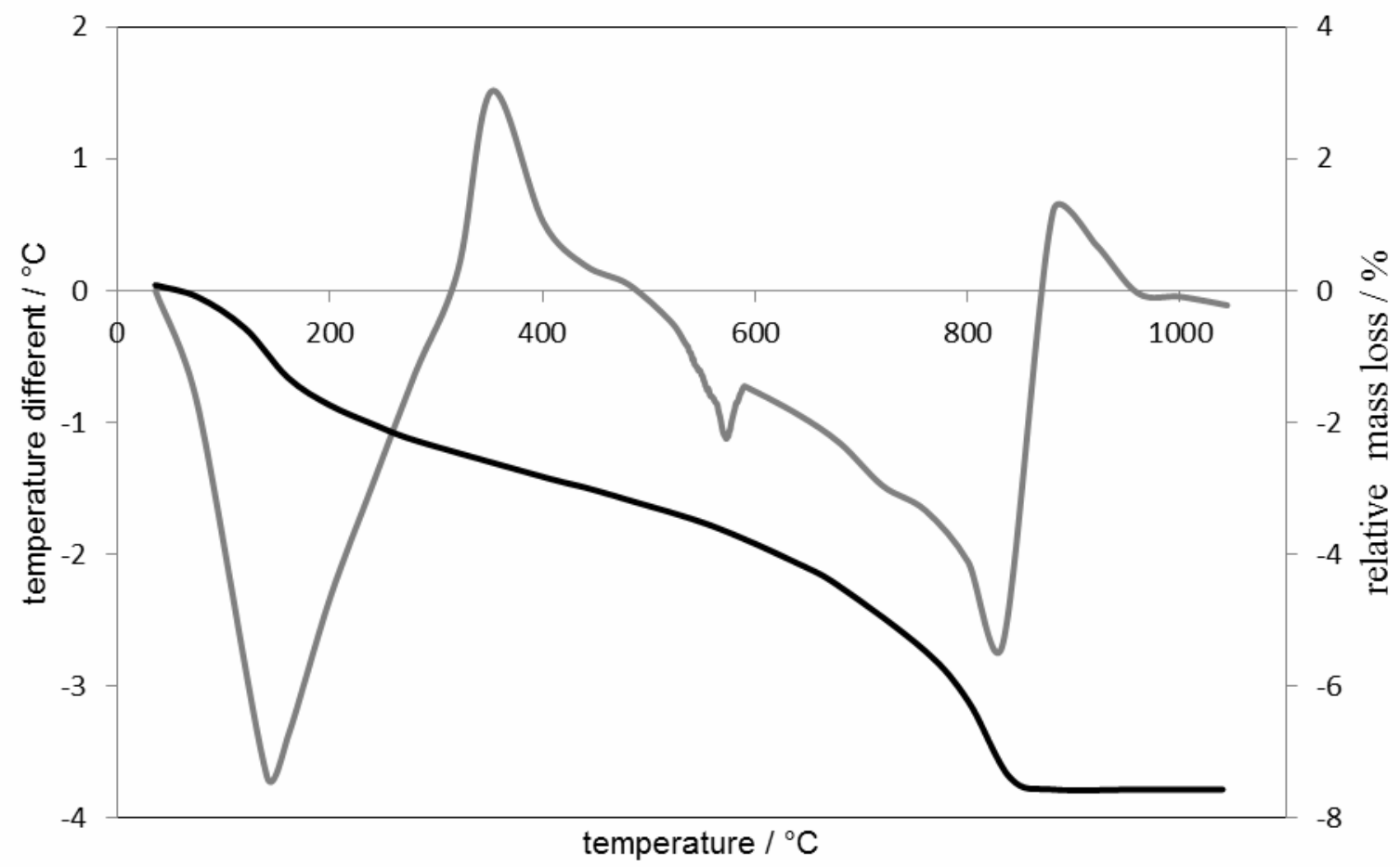

Figure 2: DTA (gray) and TG (black) of the Romanesque brick.

The second step of the mass-loss has sharp termination at $\sim 840{ }^{\circ} \mathrm{C}$ which is a typical feature of the TG curve of the decomposition of calcite [15]. Between these two significant mass losses, a gradual mass loss is present that can be explained by rhe presence of the dissociated water molecules, i.e. ions $\mathrm{H}^{+}$and $\mathrm{OH}^{-}$on the crystal surfaces. To liberate such water, higher temperature (up to $600{ }^{\circ} \mathrm{C}$ ) is necessary [16]. The second reason can be liberation of $\mathrm{OH}^{-}$, which could insert itself into dehydroxylated clay during redehydroxylation. Neither the endothermic minimum on the DTA curve, nor a step connecting with mass-loss on TG curve, which could be ascribed to the second dehydroxylation, were not registered with these analyses. Redehydroxylation is very slow process and 2300 years, when the bricks were in the 
open air, was probably not sufficiently long time for the binding of a greater amount of $\mathrm{OH}^{-}$ into the dehydroxylated clay structure. After that period, new plaster and pavement were laid onto the bricks, therefore the bricks have been protected from atmospheric moisture up to now.

The results of TD are visualized in Fig. 3. The TD of the first heating, as well as the TD of the second heating, showed the presence of a significant amount of quartz, which corresponds with a small DTA endothermic peak at $\sim 570{ }^{\circ} \mathrm{C}$. Above $700{ }^{\circ} \mathrm{C}$, the TD curve of the brick material begins to curve downwards, i.e. contraction of the sample takes place. It can be ascribed to decomposition of calcite [17]. After completion of this decomposition, the sample continues to expand up to maximum experimental temperature $1000{ }^{\circ} \mathrm{C}$. If the glassy phase were be present in the brick, it would be indicated on the both the TD curves via typical contraction caused by the pressing force of the dilatometer's push-rod [18]. This contraction appears above transformation temperature of the glassy phase. Since the glassy phase can arise during firing at temperatures higher than $1000{ }^{\circ} \mathrm{C}$, we can state that the maximum firing temperature of the historic bricks was lower than $1000^{\circ} \mathrm{C}$.

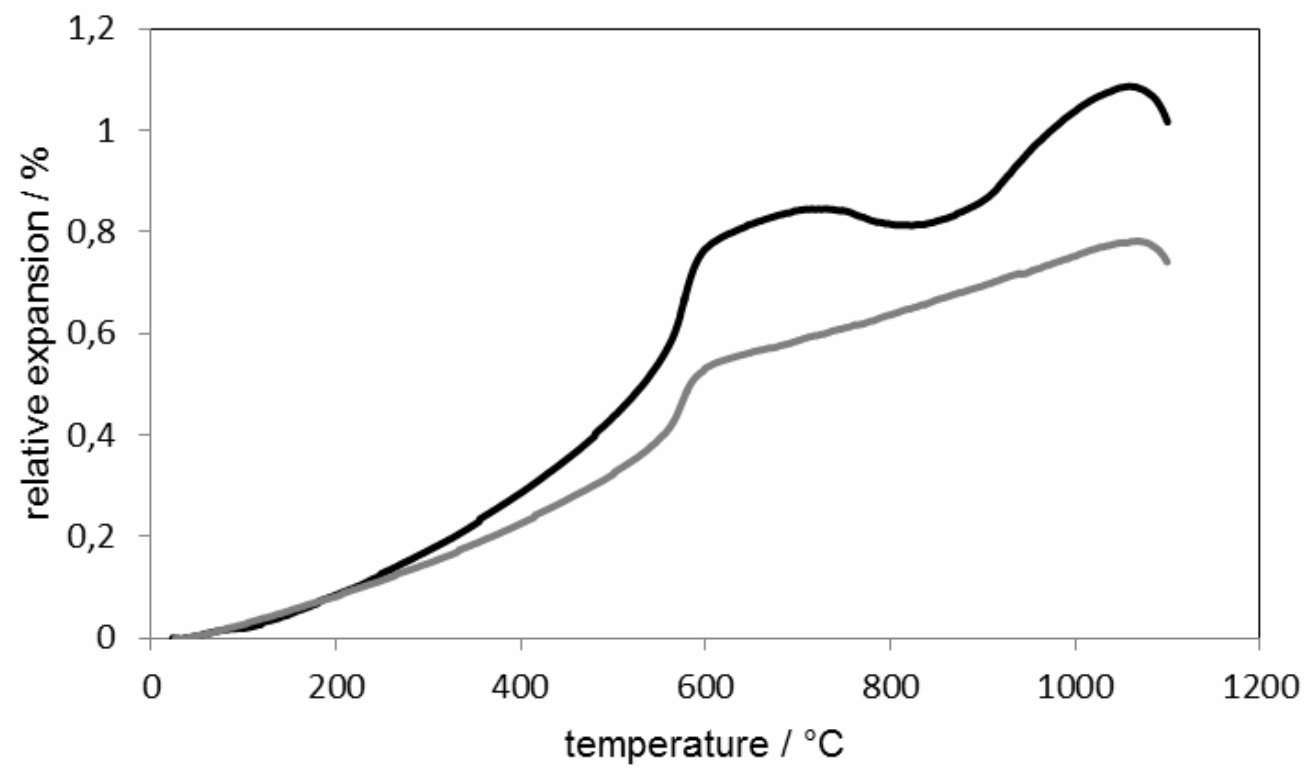

Figure 3: TD of the Romanesque brick, the $1^{\text {st }}$ (black) and $2^{\text {nd }}$ (gray) heating.

Both TD curves depicted in Fig. 3 can be used for the estimation of the firing temperature [19, $20,21]$. The thermal expansion method is based on the fact that when the partially fired clay body is undergoes an increasing temperature, the shrinkage occurs above a certain temperature. The point on the dilatometric curve where contraction starts is considered the original firing temperature. According to this rule, the temperature $\sim 700{ }^{\circ} \mathrm{C}$, which corresponds to the beginning of the contraction, is the firing temperature. 


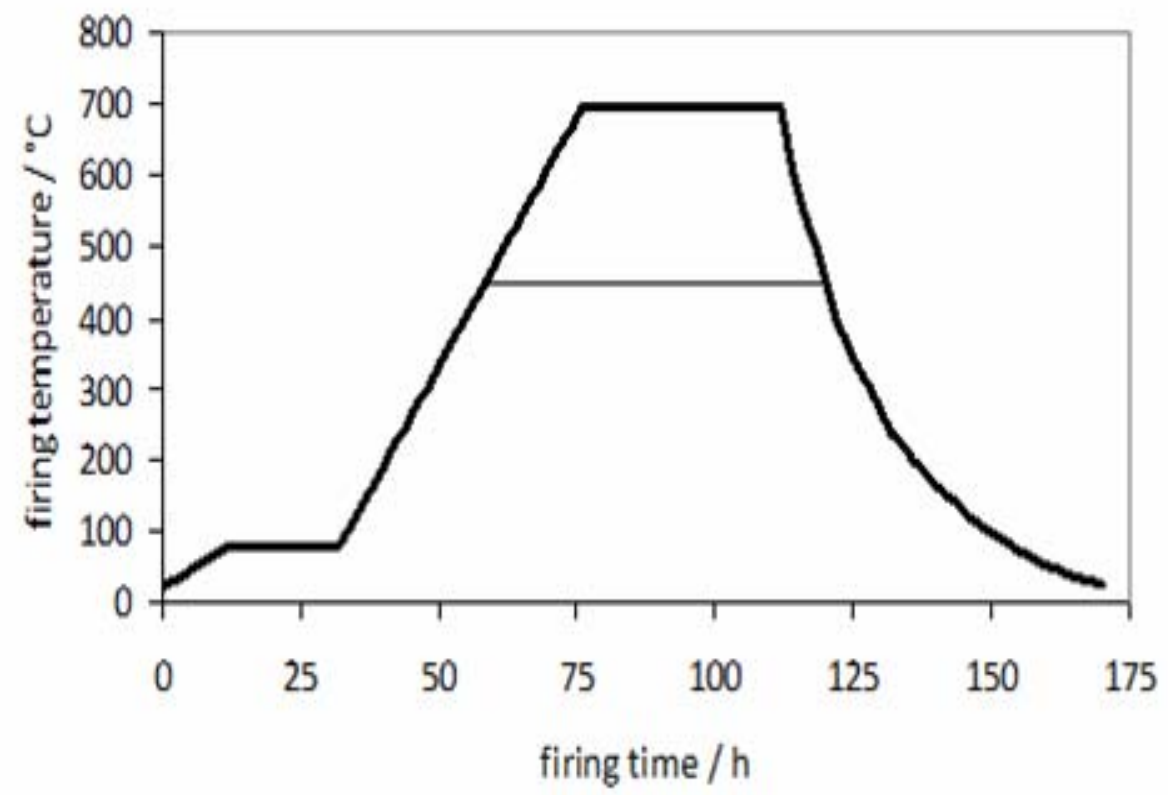

Figure 4: The firing schedule for 7-day firing. Temperatures above $450{ }^{\circ}$ Care suitable for dehydroxylation.

If we suppose a short and simple firing schedule according to Fig. 4, we see that a period with temperatures higher than $450^{\circ} \mathrm{C}$, which are suitable for dehydroxylation, is $\sim 60 \mathrm{~h}$ long for 7 day firing. The period at $700{ }^{\circ} \mathrm{C}$, where dehydroxylation runs intensively, is also sufficiently long: $\sim 35 \mathrm{~h}$. That is sufficient time for completing dehydroxylation.

As written above, the estimation of the firing temperature is based on evaluation of degree of conversion. Irreversible phase transformations, which we took into account, were dehydroxylation of phyllosicates and decomposition of calcite. A formation of a glassy phase is beyond the capability of the simple medieval kiln (heated with wood) for the firing the bricks. As mentioned above, the degree of conversion depends on the temperature and time, i.e. the same degree of conversion we can obtain with lower temperature and longer time or with higher temperature and shorter time. But the influence of the temperature is stronger than the influence of the firing duration. These conditions determine an amount of the dehydroxylated phyllosicates and calcite after firing, and consequently, the results obtained by the used method (TG, DTA, TD and XRD). Therefore, if we want to estimate the firing temperature, we should know an approximate firing schedule. If the firing at high temperatures takes sufficient time, these reactions can be completed in the whole brick's volume. After analysis of the possible firing schedule (Fig. 4), we can conclude that there was enough time to complete dehydroxylation in the whole brick's volume at the temperatures higher than $600{ }^{\circ} \mathrm{C}$ during at least $35 \mathrm{~h}$. We can say that the minimum firing temperature was $\sim 600{ }^{\circ} \mathrm{C}$. On the other side, the firing conditions were not sufficient for the total decomposition of calcite. The upper limit of the firing temperature can not be estimated from the decomposition of calcite only, which expresses itself in Fig. 2 by the mass-loss and endothermic minimum and by a contraction in Fig. 3. Besides that, we should take into 
consideration the technical limit of the kiln. It was probably not higher than $\sim 700{ }^{\circ} \mathrm{C}$. In addition, the color of the brick was light, which suggests a not high firing temperature.

\section{Conclusions}

A pavement brick taken from a Romanesque part of the church in Pác, in the Trnava County, Slovakia; it was investigated by XRD and thermal analyses DTA, TG and TD. It was found that the brick contained dehydroxylated illitic clay, calcite and quartz. As revealed, dehydroxylation was completely finished and no significant redehydroxylation was observed. Decomposition of calcite was also found. The estimated firing temperature is between $600{ }^{\circ} \mathrm{C}$ and $700{ }^{\circ} \mathrm{C}$.

\section{Acknowledgements}

This work was supported by grant VEGA 1/0646/12, Ministry of Education of Slovakia. One author (I.Š.) is indebted to prof. V.A. Drebuschchak (Novosibirsk State University, Russia) for his interest in our work and valuable comments.

\section{References}

[1] Vandiver, P. (2001). The role of materials research in ceramics and archeology. Annual Review of Materials Research. 31, 373-385. 10.1146/annurev.matsci.31.1.373.

[2] Drebuschak, V.A., Mylnikova, L.N. \& Drebuschcak, T.N. (2011). The mass-loss diagram for the ancient ceramics. Journal of Thermal Analysis and Calorimetry. 104 (2), 459-466. 10.1007/s10973-010-1230-x.

[3] Ondruška, J., Trník, A. \& Vozár, L. (2011). Degree of conversion of dehydroxylation in a large electroceramic body. International Journal of Thermophysics. 32 (3), 729-735. 10.1007/s10765010-0899-1.

[4] Ondruška, J., Trník, A. \& Medved', I.. (2011) Estimation of mass transfer parameters during dehydroxylation in a large ceramic body by inverse methods. Ceramics International. 37 (8), 3293-3305. 10.1016/j.ceramint.2011.05.126.

[5] Kováč, F. (1960). Firing of bricks in the field kilns (in Slovakian). Bratislava: Dom techniky.

[6] Laefer, D.F., Boggs, J. \& Cooper, N. (2004) Engineering properties of historic brick -variability considerations as a function of stationary versus nonstationary kiln type. Journal of the American Institute of Conservation of Historic and Artistic Works. 4 (3), 255-272.

[7] Monteiro, S.N., Vieira, C.M.F. \& Carvalho, E.A. (2005). Technological behavior of red ceramics incorporated with brick waste. Revista Matéria. 10 (4), 537-542.

[8] Podoba, R., Trník, A. \& Podobník, L'. (2012) Upgrading of TGA/DTA analyzer Derivatograph. Épitöanyag. 64 (1-2), 28-29.

[9] Štubňa, I., Vážanová, A., Varga, G. \& Hrubý, D. (2007). Simple push-rod dilatometer for dilatometry of ceramics. In Proceedings of the Conference Research and teaching of physics in the context of university education, June 5 and 62007 (69-74). Nitra: SUA in Nitra.

[10] Štubňa, I. \& Kozík, T.: (1997). Permeability of the electroceramics to gas and its dependence on the firing temperature. Ceramics International. 23 (3), 247-249. 
[11] Norton, F.H. (1970). Fine ceramics technology and applications. New York: McGraw-Hill Co.

[12] Podobník, L., Jankula M. \& Štubňa, I. (2012). Influence of dehydroxylation on hydration of illitic and kaolinitic clays. In XXV DIDMATTECH 2012 Book of Abstracts, September $10^{\text {th }}$ $13^{\text {th }} 2012$ (20-21). Komárno: JSU Komárno.

[13] Drebuschak, V.A., Mylnikova, L.N. \& Molodin, V.I. (2007). Thermogravimetric investigation of ancient ceramics. Journal of Thermal Analysis and Calorimetry. 90 (1), 73-79. 10.1007/s10973-007-8478-9.

[14] Drebuschak, V.A., Mylnikova, L.N., Drebuschcak, T.N. \& Boldyrev, V.V. (2005). The investigation of ancient pottery - Application of thermal analysis. Journal of Thermal Analysis and Calorimetry. 82 (3), 617-626. 10.1007/s10973-005-0942-9.

[15] Teleki, A., Vozár, L. \& Tóth, A. (2008). Kinetics of the irreversible chemical process (in Slovakian). In Cophys - International Physics Workshop, June $19^{\text {th }} 2008$ (99-107). Nitra: CPU in Nitra.

[16] ONIITECHIM. (1978). Firing of kaolin and investigation of fired products (in Russian). PhD thesis stored in Čerkassy, No. 1762178: Kiselev, I.M.

[17] CPU in Nitra. (2009). Physical properties of lime before and after firing (in Slovakian). PhD thesis stored in Nitra: Tóth, A.

[18] Ventureli, C. \& Paganelli, M. (2007). Sintering behavior of clays for the production of ceramics. Cfi/Ber. DKG. 84 (5), E1-E3.

[19] Tite, M.S. (1969). Determination of the firing temperature of ancient ceramics by measurement of thermal expansion: a reassessment. Archaeometry. 11 (1), 131-143. 10.1111/j.14754754.1969.tb00636.x.

[20] Roberts, J.P. (1963). Determination of the firing temperature of ancient ceramics by measurement of thermal expansion. Archaeometry. 6 (1), 21-23. 10.1111/j.14754754.1963.tb00574.x.

[21] Petrovič S., Jovanov, V., Vujovič, S. \& Ranogajec. J. (2007) Historical materials from the medieval fortress Bač. Processing and Applied Ceramics. 1 (1-2), 75-80. 